\title{
Mobile learning, a solution to vocational training in Senegal
}

\author{
Marie Hélène Wassa \\ Mballo/PhD student \\ Cheikh Anta Diop University \\ Dakar, Senegal
}

\author{
Richard Hotte/Researcher \\ Research center \\ LICEF,TELUQ \\ Montreal, Canada
}

\author{
Alassane Diop \\ researcher \\ Alioune Diop University \\ Bambey, Senegal
}

\author{
Ibrahima Niang \\ researcher \\ Cheikh Anta Diop University \\ Dakar, Senegal
}

\begin{abstract}
This article focuses on the issue of the use of mobile technologies, especially on online Laboratories, as a support to professional development of adults in the work situation in Senegal. More specifically, how mobile learning can be a solution to access to education for nomadic professionals working specifically in the area of computer networks? This issue is at the heart of a doctoral research underway in the context of the creation of the Senegalese Virtual University (SVU) primarily to adequately solve the problem of mass enrollment in university.
\end{abstract}

Index Terms - mobile learning, online laboratory, collaborative learning

\section{INTRODUCTION}

The Senegalese virtual university which opened its doors in January 2014 is a sure solution to mass enrollments in university. In this desire to meet physical and human infrastructure shortages in higher education, virtual universities are springing up all over West and North Africa. Virtual University is essentially characterized by training offers completely online

Distance learning, especially online learning is growing and is the subject of several research projects. The success of this mode of learning is related in large part to advances in information technology and communication (ITC). Indeed, online learning is a component of distance education for students, individuals, employees and businesses. To reflect the mobility of some learners who may be facing the spacetemporal problem, mobile learning is proposed so that their training be via a mobile device (smartphone, tablet and other). Also in the progress of distance education, laboratories are not exception. Indeed the concept of online lab makes possible remote handling and online without having to visit a physical local. The online labs provide the learner with more flexibility and autonomy for his/her development.

Professionals are often faced with the problem of mobility and space to do their development. The question that arises is what learning mode can be proposed to them based on their space-temporal constraint?

The solution best suited to professionals is to offer them a mobile learning system that meets the needs of development while on the move. This solution is completed by the integration of online laboratory.
This proposal will be developed later in the first paragraph of this article on mobile technology and university education. The second item will show the progress of work on mobile learning and online labs and we will conclude with research perspectives.

\section{MOBILE TECHNOLOGY AND UNIVERSITY EDUCATION}

Online learning is made possible by universities, companies, institutes. Universities that offer only online courses are called virtual universities.

In terms of experience on online education, some faculties of the University Cheikh Anta Diop (UCAD) are beginning to incorporate it into their training.

Most of the students enrolled in online courses are professionals who have access to online courses through a computer or laptop with internet connection.

The Faculty of Science and Technology Education and Training (FASTEF) offers distance education for people working in the education sector. The results given by the FASTEF found a retention rate of $76.36 \%$ and a success rate of $81.94 \%$. The Distance Learning Centre (ERC) is funding the World Bank launched since 2000. Targets of this training are often the professional world. The CISCO Networking Academy program was launched in Senegal since 2003. Currently 36 local functional academies are involved in this program via the CISCO Regional Academy UCAD.

We believe that the development of access to online learning, providing the necessary resources, will reduce the rate of rural exodus. Indeed, Dakar, Senegal administrative and economic capital, has $20.6 \%$ of the population, according to 2011 statistics. This inequality can be explained by a high concentration of institutions of vocational training structures and technical and higher education in the region of Dakar, with rates of $45.1 \%$ and $78.7 \%$ schools.

These online courses offered in higher education show the political will of the state of Senegal to implement the Senegalese Virtual University (SVU). The SVU will help increase enrollment in higher education. This is also a solution to the lack of reception facilities on the one hand, and secondly, the lack of resource persons.

Mobile technology brings about major changes in our lives every day. Past the landlines, we are in the era of smart phones. This mobile technology provides instant communication. It 
helps to optimize work to inform in real time and to learn. $90 \%$ of the world's population subscribes to mobile cell phones; this indicates the importance of work in the field of mobile technology. Advances in mobile technology interfere in the world of education hence the concept of mobile learning, which is defined as the act of learning using mobile devices and wireless technologies in order to promote learner mobility.

In Africa, mobile learning is not well adapted into the education system. But advances in mobile technology indicate that the continent is ready to adopt it.

Here, we find that the rate of mobile phone subscribers and the Internet has increased dramatically. The Global System for Mobile Communications Association (GSMA) 2015, note 915 million mobile users with an estimated population of over one billion inhabitants. Currently, we can count hundreds of mobile applications developed by Africans. An extract from the 2013 UNESCO to give an example: in South Africa, Nokia Momath project uses SMS (Short Message Service) functions of standard mobile phones to provide students access to content and support mathematics [1].

Returning to our country in case, Senegal where rates of Internet subscribers increased from 3.9\% in June 2012 to $9.02 \%$ in June 2013. Mobile Internet use of student jumped to $88.7 \%$. This means that the introduction of mobile learning is not a problem in Senegal.

In the 90 's, there had been a surge in projects that tend to integrate mobile devices in the offers of training institutes of higher education [2][3][4][5][6][7][8].

Mobile learning can be a real opportunity for professionals. Mobile learning provides professional development as well as it can improve working conditions. [9][10][11][12][13].

The emergence of remote labs makes possible remote handling and online without having to visit a physical local. Remote laboratories can be considered as a support to teaching. In fact they provide the learner with more flexibility and autonomy for his/her development. In addition, they offer the learner an opportunity to collaborate with peers for a better understanding of the activity. Many projects of remote laboratory have emerged since the early 20th century [14][15][16][17][18][19].

\section{STATE OF THE WORKS}

Distance education is growing and is the subject of several research projects. Indeed, we see mobile learning which results in access to training opportunities with mobile devices. Another interesting thing to note is the ability to do work online that is based on online labs.

Mobile devices are gaining ground around the world, so mobile learning is now the subject of several research projects. Thus mobile learning is integrated into formal learning through the introduction of mobile devices to better enrich courses in situ [1].

Many universities around the world integrate mobile learning into their training. This form of learning can be done in the presence of the trainee or remotely.
The growth of mobile technology has led to the development of collaborative applications [20]. For mobile devices to be more efficient for exchanging information between users and so they can support mobile working, the design of collaborative editing applications must carefully take into account the constraints of these systems: limited memory, power limited processing, limited bandwidth, etc. This collaboration between devices only allows users to edit a document at the same time.

The emergence of online labs makes possible remote handling and online without having to visit a physical local. Remote laboratories can be considered a support to teaching. In fact they provide the learner with more flexibility and autonomy for his/her development.

Laboratory collaborative online is very recent and is the subject of several research not yet available to learners. The implementation of such laboratories requires knowledge of:

- Cognitive Science: Combines the online labs to learning theories. The impact of online labs in the learning process of a learner is of key importance

- Science and Engineering: designing a collaborative learning system via online labs.

A baseline study of mobile learning and online laboratories will show that a focus is made on the collaboration between learners. This is very recent in scientific work and may be subject to research. This leads us to take a ride on collaborative learning.

Collaborative learning is an approach that gives a lot of freedom to the learner [21]. Indeed, learners manage much of their group work. ICT developments in the field of online learning have led to the computer -supported collaborative learning. To go further in this process, we combine computersupported collaborative learning and online laboratories, which gives birth to collaborative online laboratories [14].

The main challenges that we face in our research are on the one hand, the constraints of mobile devices with regard to limited memory, limited processing power, limited bandwidth, battery life and, other hand, at the level of remote labs, it is able to keep the operational benefits and educational physical laboratory Indeed such a system must provide interactivity between users, sustainability of experiences so that the learner can access this at any time, requiring regular maintenance. Account must be taken of the variation of the load of a network to ensure real-time manipulation.

\section{RESEARCH PERSPECTIVES}

We plan to implement a mobile learning system with functionality like setting up a laboratory collaborative online accessible via mobile devices. Indeed, we put a fundamental emphasis on collaboration.

Mobile learning is proving to be a real opportunity for professionals who face a real problem of time and space because of their high mobility. Such a learning system that we propose will strengthen the running of training proposed by the newly opened Senegalese virtual university. 
However, our review of the literature allows us to identify a number of research perspectives that are not or poorly developed in the scientific journal:

- Formalize mobile learning: learning to apply a theory of mobile learning

- Collaborative online laboratories: ensure data consistency for remote lab learners

- Handle online labs via mobile devices: provide access and manipulation of remote labs algorithms via mobile devices taking into account the various constraints.

Thus, in this context, a mobile learning system is proposed as a feature with the establishment of a laboratory collaborative online accessible via mobile devices.

In this system we are proposing, collaboration will occur at two levels:

- Collaboration of learners via mobile devices

- System Collaboration: Collaborative online labs

The use of mobile devices in the online labs enriches the learning system. However, ensuring collaboration between mobile learners on the one hand, and online labs on the other hand, presents a challenge, according to the constraints mentioned in the previous section.

Thus, in the result of our work, we will focus on:

- The learning mode that will be associated with the online labs;

- The computer learning system;

- The system of communication between learners and the laboratory;

- A collaborative editing algorithm in mobile devices to ensure data consistency;

- A format mode, representation and display of data and information of the remote laboratory.

So far in the progress, the integration of mobile devices in the online labs is a project in progress [22]. We intend to go further in our thesis aiming to achieve a collaborative learning system supported by mobile device.

In our general architecture (Fig. 1), mobile application systems send requests to the main server based in a site. The job of the main server is to transmit the requests to the cloud computing. The main server checks the authentication, authorization and traceability of the various mobile devices.

Cloud computing is composed of three servers

- One access server which is used for identifying and checking the various accesses

- One application server which ensures the collaboration between various devices, as well as the discovery of the services which permit access to courses materials.

- One calculation server which deals with data recording, and tasks handling. This server also takes care of the access to the laboratory in case scientific tests are to be made.
An access network (internet, private network....) enables connection with cloud computing. The main servers in the various sites help to avoid bottlenecks in the access server.

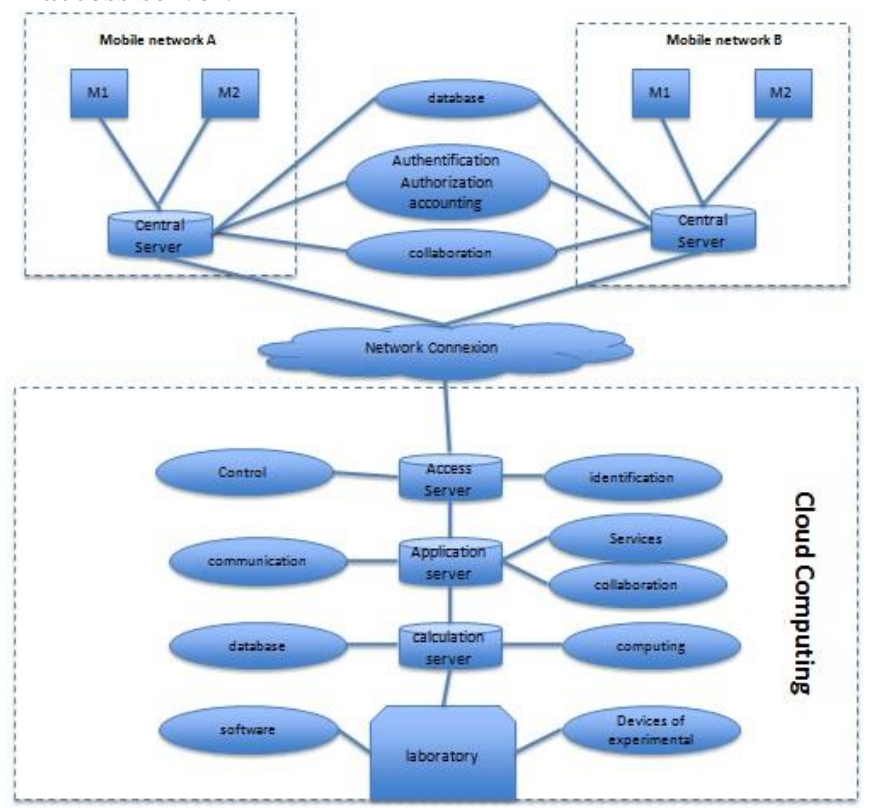

Fig. 1: Architecture of the mobile application system

A handy example of this general architecture use may be the configuration of a computer network. The following figure shows this type of use.

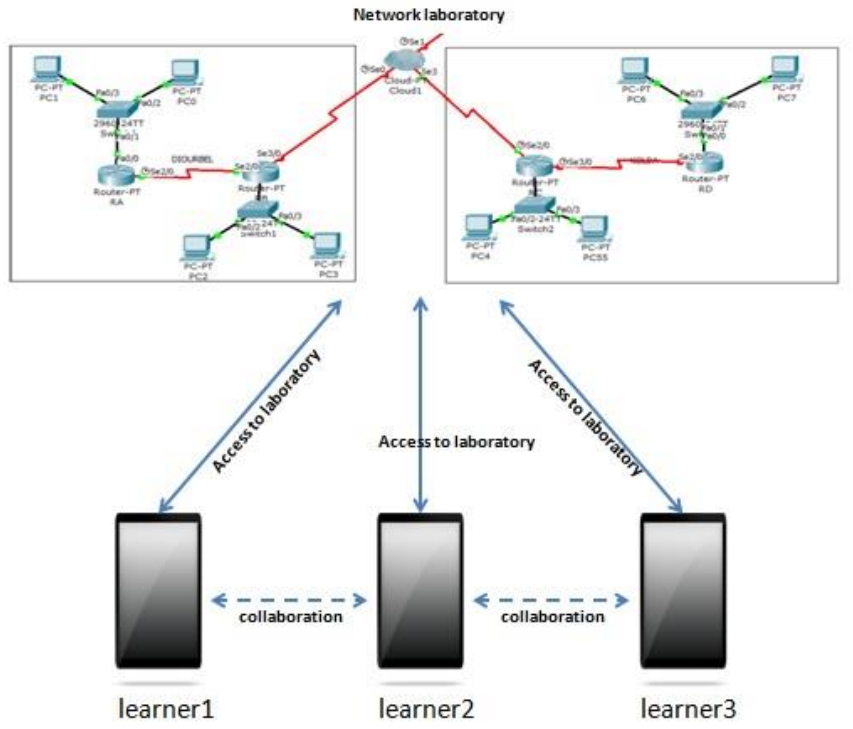

Fig. 2: example of mobile learning system

\section{CONCLUSION}

In this article, we have established a scientific journal on mobile learning, and online laboratories. This journal allows us to take stock of the existing before continuing our thesis that focuses on the implementation of a mobile learning system following the establishment of the Senegalese Virtual 
University. The functionality of our system is the realization of a laboratory collaborative online accessible via mobile devices. The main limitations noted in our state of the art pushes us to continue our research on the following aspects: the learning mode, the computer system, the collaborative editing algorithm in mobile devices.

\section{REFERENCES}

[1] UNESCO, "the future of mobile learning: implications for planning and policy formulation," Paris, 2013.

[2] Sharples, "The Design of Personal Mobile Technologies for Lifelong," Computer and Education, pp. 177-193, 2000.

[3] Sharples, Corlett and Westmancott, "The Design and Implementation of a Mobile Learning Resource," Personal and Ubiquitous Computing, pp. 220-234, 2002.

[4] Bormida, Bo, Lefree and Taylor, "An Open Abstract Framework for Modeling Interoperability f Mobile Learning Services," European Journal of Engineering for Information Society Applications, 2003.

[5] ACU, "ACU business students integrate iPads into innovate study abroad experience," 2010, June 11. Retrieved September 13, 2013, From http://www.acu.edu/news/2010/100611_iPadinOxfor d.html.

[6] M. Ally and A. Palalas, "State of Mobile Learning in Canada and Future Directions," Canada, 2011.

[7] HistoQuizz, 2013. Retrieved September 30, 2013, from http://www.ludovia.com/2013/09/lapplicationhistoquizz-ipad-fait-entree-les-salles-classe/.

[8] Brian, "Bucks Unveils First Mobile App," 2010, May 24.retrieved September 13, 2013 from. http://buckslib.wordpress.com/2010/05/24/bucksunveils-first-mobile-app/.

[9] M. Sharples, "Mobile learning: research, practice and challenges," Distance Education in China, pp. 5-11, 2013.

[10]O. Smordal and J. Gregory, "Personal Digital Assistants in medical education and practice," Journal of Computer Assisted Learning, pp. 320-329, 2003.

[11] K. Schrader, T.-N. Nguyen-Dobinsky, K. Kayser and T. Schrader, "Mobile education in autopsy conferences of pathology: presentation of complex cases,” 2006, November 09. Retrieved September 30, 2013

from http://www.diagnosticpathology.org/content/1/1/42.

[12]L. Gjedde, "The Flex-learn project: designing a mobile learning platform for truck drivers," 2008, May. Retrieved September 30, 2013 from http://www.mobilemonday.dk/wp-

content/uploads/May08_Presentations/Lisa\%20Gjedd e\%20-

$\%$ 20Designing\%20A\%20Mobile\%20Learning\%20P1 atform\%20For\%20Truck\%20Drivers.pdf.

[13] Derycke, V. Chevrin and T. Vantroys, "P-Learning and e-Retail: a case study and a flexible Software Architecture," Proceedings of Pervasive Learning: Design Challenges and Requirements, Toronto, Canada, 2007.

[14] Gravier, J. Fayolle, B. Bayard, M. Ates and J. Lardon, "State of the art about remote laboratories paradigms-foundations of ongoing mutations," International Journal of Online Engineering, 2008.

[15] K. Taylor and J. Trevelyan, "Australia's telerobot on the web," 26th Symposium on Industrial Robotics, Singapore, 1995. pp 39-44.

[16]J. Trevelyan, "Lessons learned from 10 years experience with remote laboratories," International Conference on Engineering Education and Research Progress through Partnership, Czech Republic, 2004.

[17] Salzmann, D. Gillet and P. Huguenin, "Introduction to Real-time control using LabVIEW with an Application to Distance Learning," Journal of Engineering Education, 2000.

[18] J. Del Alamo, V. Chang, J. Hardison, G. Mishuris, L. Brooks, C. Mclean, V. Chan and L. Hui, "Educational experiments with an online microelectronics characterization laboratory," Proceedings of International Conference on Engineering Education, Manchester, 2002.

[19]T. Schafer, J.-M. Seigneur and A. Donnelly, "PEARL: A generic architecture for live experiments in a remote laboratory," ICSEE2003 conference, Dublin, 2002.

[20] M. Ahmed-Nacer, P. Urso, C.-L. Ignat and G. Oster, "Evaluation of the memory occupancy CRDTs for real-time collaborative editing mobile," UbiMobFrench-speaking conference on Mobility and Ubiquity Computing, 2012.

[21] S. George, "Collective learning remote. SPLACH: a computing environment supporting a project teaching," thesis, 2001.

[22] May, C. Terkowsky, T. Haertel and C. Pleul, "The laboratory in your hand-Making remote laboratories accessible through mobile devices," IEEE Global Engineering Education Conference (EDUCON), Berlin, 2013. 